\title{
Crackle Pitch and Rate Do Not Vary Significantly During a Single Automated-Auscultation Session in Patients With Pneumonia, Congestive Heart Failure, or Interstitial Pulmonary Fibrosis
}

\author{
Andrey Vyshedskiy PhD, Sadamu Ishikawa MD, and Raymond LH Murphy Jr MD
}

\begin{abstract}
OBJECTIVE: To determine the variability of crackle pitch and crackle rate during a single automated-auscultation session with a computerized 16-channel lung-sound analyzer. METHODS: Forty-nine patients with pneumonia, 52 with congestive heart failure (CHF), and 18 with interstitial pulmonary fibrosis (IPF) performed breathing maneuvers in the following sequence: normal breathing, deep breathing, cough several times; deep breathing, vital-capacity maneuver, and deep breathing. From the auscultation recordings we measured the crackle pitch and crackle rate. RESULTS: Crackle pitch variability, expressed as a percentage of the average crackle pitch, was small in all patients and in all maneuvers: pneumonia $11 \%$, CHF $11 \%$, pulmonary fibrosis $7 \%$. Crackle rate variability was also small: pneumonia $31 \%$, CHF $32 \%$, IPF $24 \%$. Compared to the first deepbreathing maneuver $(100 \%)$, the average crackle pitch did not significantly change following coughing (pneumonia 100\%, CHF 103\%, IPF 100\%), the vital-capacity maneuver (pneumonia $100 \%$, CHF 92\%, IPF 104\%), or during quiet breathing (pneumonia 97\%, CHF 100\%, IPF 104\%). Similarly, the average crackle rate did not change significantly following coughing (pneumonia $105 \%$, CHF $110 \%$, IPF 90\%) or the vital-capacity maneuver (pneumonia 102\%, CHF 101\%, IPF 99\%). However, during normal breathing the crackle rate was significantly lower in the patients with pneumonia $(74 \%, P<.001)$ and significantly higher in the patients with IPF $(147 \%, P<.05)$ than it was during deep breathing. In patients with CHF the average crackle rate during normal breathing was not significantly different from that during the first deep-breathing maneuver $(\mathbf{1 0 8 \%})$. CONCLUSIONS: Crackle pitch and rate were surprisingly stable in all 3 conditions. Neither crackle pitch nor crackle rate changed significantly from breath to breath or from one deepbreathing maneuver to another, even when the maneuvers were separated by cough or the vitalcapacity maneuver. The observation that crackle rate is a reproducible measurement during one automated-auscultation session suggests that crackle rate can be used to follow the course of cardiopulmonary illnesses such as pneumonia, IPF, and CHF. Key words: auscultation; crackles; pitch; pneumonia; congestive heart failure; pulmonary; fibrosis. [Respir Care 2011;56(6):806-817. (C) 2011 Daedalus Enterprises]
\end{abstract}

\section{Introduction}

Lung sounds detected over the chest reflect the underlying pulmonary pathophysiology. Advances in acoustic

Drs Vyshedskiy and Murphy are affiliated with Brigham and Women's/ Faulkner Hospital, Boston, Massachusetts. Dr Ishikawa is affiliated with St Elizabeth Medical Center, Boston, Massachusetts.

Dr Murphy and Dr Vyshedskiy have disclosed a relationship with Stethographics. technology now allow precise detection and quantification of lung sounds, so we have been studying computerized lung-sound analytic methods under the assumption that

\footnotetext{
This research was partly supported by National Institutes of Health grant SBIR 1R43HL091840-01, and a grant from Stethographics.

Correspondence: Andrey Vyshedskiy PhD, Brigham and Women's/ Faulkner Hospital, 1153 Centre Street, Suite 40, Boston MA 02130. E-mail: av@stethographics.com.
}

DOI: $10.4187 /$ respcare.00999 


\section{Crackle Pitch and Rate Do Not Vary Significantly During Automated-Auscultation}

this technology can improve diagnosis and monitoring of cardiopulmonary disorders. Numerous studies support the hypothesis that computerized lung-sounds analysis has clinical value ${ }^{1-5}$ and can identify sounds as well as experienced clinicians do. ${ }^{4,6}$

Crackles are important abnormal lung sounds. The degree of profusion of crackles often reflects the severity of disease. Clinicians have long recognized that crackles often increase in number as congestive heart failure (CHF) worsens, and that crackles are more numerous in late-stage than in early-stage interstitial pulmonary fibrosis (IPF). Crackles are common in patients with pneumonia and often clear when pneumonia resolves. Unfortunately, there is substantial observer variability in auscultation findings, so auscultation has been considered unreliable. Fortunately, that situation has changed. Automated computerized crackle counting, introduced over 2 decades ago, eliminates inter-observer variability and allows longitudinal crackle monitoring, ${ }^{6}$ which could aid in following the course of various illnesses. Accordingly, we are interested in how much the measurement of crackle pitch (spectral frequency) and crackle rate changes between breaths. If the crackle pitch or crackle rate varies greatly from breath to breath, it would be difficult to interpret this measurement as an indicator of improvement or worsening of illness. Crackles can be present due to atelectasis, and deep breathing is associated with clearing of this type of crackles. They can also be caused by secretions in the airways. To examine whether these variables influence crackle pitch and crackle rate we studied automated auscultation recordings from before and after deep breathing and cough, in patients with pneumonia, CHF, and IPF, as crackles are common in those disorders. Specifically, then, our objectives were to determine the within-maneuver crackle variability and the influence of breathing effort and cough on the crackle pitch and crackle rate in patients with pneumonia, CHF, and IPF during a single automated-auscultation session.

\section{Methods}

This study was approved by the institutional review board of Brigham and Women's/Faulkner Hospitals, and written consent was obtained from all patients or their next of kin. Patients were recruited from a pool of patients who had undergone lung-sounds analysis as a part of a broader study of the correlation of disease processes with lungsounds patterns. We identified hospitalized and out-patients of a community teaching hospital who were diagnosed with a specific cardiopulmonary disease or were considered normal by their clinicians. The study was not with consecutive patients; rather, this is a convenience sample, and we currently have over 1,000 patients with both a diagnosis and lung-sound recordings and analysis. The diagnostic category of each patient was made by the

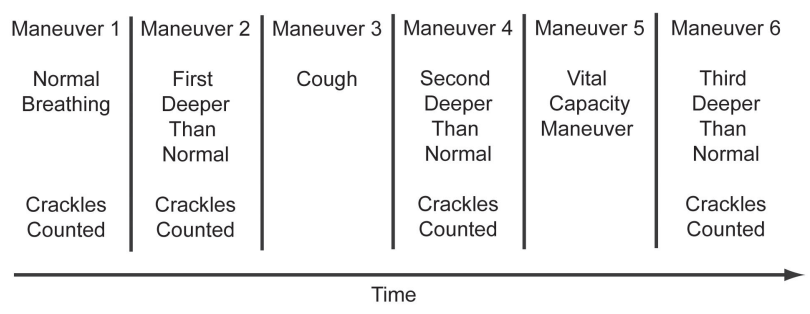

Fig. 1. Sequence of breathing maneuvers performed by patients. In this study we discuss the lung sounds only from maneuvers 1 , 2,4 , and 6.

patient's clinicians. The CHF and pneumonia patients were in-patients in a teaching hospital, and the diagnoses were confirmed by board-certified specialists. The IPF patients were out-patients and were all seen by pulmonary specialists. Among the 148 patients diagnosed with pneumonia, CHF, or IPF and who had performed all 4 breathing maneuvers, we identified 119 who had more than 2 crackles per breath during deeper-than-normal breathing and a wheeze/rhonchus rate $<20 \%$ (wheezing can obscure crackles). We enrolled 49 patients with pneumonia (23 males, mean \pm SD age $61 \pm 18 \mathrm{y}$, age range $21-85 \mathrm{y}), 52$ with CHF (33 males, age $72 \pm 13 \mathrm{y}$, age range $42-93 \mathrm{y}$ ), and 18 with IPF (11 males, age $72 \pm 14 \mathrm{y}$, age range $36-89$ y).

The subjects underwent automated auscultation with a 16-channel lung-sound analyzer (STG1602, Stethographics, Boston, Massachusetts,) described previously, ${ }^{7-10}$ which uses 14 electret condenser microphones embedded in a soft foam pad that is positioned at a $45^{\circ}$ angle on a stretcher or a plastic reclining chair. The subject lies recumbent on the microphone pad and each breathing maneuver is recorded for 20 seconds. Typically, 3-6 full breaths are recorded with each maneuver.

All the patients performed the following sequence of breathing maneuvers:

1. Normal breathing

2. Deeper than normal breathing

3. Coughing

4. Deeper than normal breathing

5. A vital-capacity maneuver

6. Deeper than normal breathing

Only data from maneuvers $1,2,4$, and 6 are reported here (Fig. 1). Crackles were not analyzed during the coughing and the vital-capacity maneuvers. The lung-sound analyzer automatically identifies and quantifies several acoustic variables, including crackle pitch and crackle rate. Crackles were defined in accordance with accepted criteria. ${ }^{11,12}$ This lung-sound analyzer has been validated as a crackle counter. ${ }^{6}$ Crackle pitch was measured from the crackle waveform, as the inverse duration (in seconds) of one complete sinusoidal cycle. ${ }^{7,10} \mathrm{We}$ use the term crackle pitch instead of crackle frequency to avoid a common 


\section{Crackle Pitch and Rate Do Not Vary Significantly During Automated-Auscultation}

Table 1. Average Tracheal Amplitude

\begin{tabular}{lcccc}
\hline \hline & $\begin{array}{c}\text { Normal } \\
\text { Breathing }\end{array}$ & $\begin{array}{c}\text { First Deeper } \\
\text { Than Normal* }\end{array}$ & $\begin{array}{c}\text { Second Deeper } \\
\text { Than Normal }\end{array}$ & $\begin{array}{c}\text { Third Deeper } \\
\text { Than Normal }\end{array}$ \\
\hline Pneumonia & $64 \pm 36$ & 100 & $100 \pm 49$ & $122 \pm 58$ \\
Congestive heart failure & $67 \pm 87$ & 100 & $86 \pm 73$ & $97 \pm 127$ \\
Interstitial pulmonary fibrosis & $51 \pm 33$ & 100 & $89 \pm 49$ & $112 \pm 87$
\end{tabular}

* The first deeper-than-normal breathing maneuver is the reference level (100\%). The other values are expressed as a percentage of that reference level (mean \pm SD).

confusion with another meaning of the word frequency: how many crackles occur per unit time.

To calculate between-maneuver crackle rate variability, we compared each patient's crackle rate during the first deeper-than-normal breathing to his or her crackle rate during each of the other breathing maneuvers. The crackle rate in each maneuver is expressed as a percentage of the crackle rate during the first deeper-than-normal breathing maneuver. Similarly, to calculate between-maneuver crackle pitch variability we compared each patient's crackle pitch during the first deeper-than-normal breathing to his or her crackle pitch during each of the other maneuvers. The crackle pitch in each maneuver is expressed as a percentage of the crackle pitch during the first deeper-thannormal breathing maneuver.

To calculate within-maneuver crackle rate variability in each patient, we calculated the standard deviation in crackle rate measured in all consecutive breaths and expressed it as a percentage of the average crackle rate during the complete 20 -second recording. Similarly, to calculate within-maneuver crackle pitch variability we calculated the standard deviation in crackle pitch measured in all consecutive breaths and expressed it as a percentage of the crackle pitch during the complete 20 -second recording.

Ventilation was monitored with a tracheal microphone. This method provides an estimate of air flow. At the flow rates we used in this study, tracheal air flow is proportional to the root mean square of the sound amplitude: doubling the air flow results approximately in doubling the root mean square of the sound amplitude. In this paper we refer to the tracheal microphone root mean square as the tracheal amplitude. Judging by the tracheal amplitude, patients on average almost doubled their air flow during deep breathing, compared to normal breathing (Table 1). We compared each patient's average tracheal amplitude during the first deeper-than-normal breathing to his or her tracheal amplitude in each of the other maneuvers. The tracheal amplitude in each maneuver is expressed as a percentage of the tracheal amplitude during the first deeper-than-normal breathing maneuver. The difference in tracheal amplitude between the 3 deeper-than-normal maneuvers was not statistically significant.

The results are presented as mean \pm SD unless otherwise stated. We used the Student $t$ test to compare the variables between the groups. $P<.05$ was considered significant.

\section{Results}

\section{Within-Maneuver Crackle Variability}

To compare crackle pitch (ie, spectral frequency) and crackle rate between breaths within each maneuver, we express the crackle pitch or rate in each breath as a percent of the crackle pitch or rate in the first breath (Fig. 2). There were no statistically significant differences in crackle pitch or crackle rate between the breaths, in all 3 conditions. Neither crackle pitch nor crackle rate consistently increased or decreased between consecutive breaths.

We calculated the average crackle pitch in each breath and in each maneuver. There was little variability in crackle pitch within all the breathing maneuvers, in all 3 conditions (Table 2). Table 3 shows the average crackle pitch in a 20 -second recording.

We calculated crackle rate for each breath and each maneuver, and there was no significant within-maneuver variability (Table 4), in all breathing maneuvers, in all 3 conditions. Table 5 shows the average crackle rate in a 20 -second recording.

\section{Between-Maneuver Crackle Variability}

We compared each patient's average crackle pitch during the first deeper-than-normal breathing to his or her crackle pitch during each of the other maneuvers, and we express the crackle pitch in each maneuver as a percentage of the crackle pitch during the first deeper-than-normal breathing (Table 6). Surprisingly, we found very little variation in crackle pitch between the breathing maneuvers, in all 3 conditions.

Figure 3 shows examples of between-maneuver crackle rate variability in individual patients with pneumonia, $\mathrm{CHF}$, and IPF. As compared to normal breathing, the crackle rate increased during deep breathing in the pneumonia patient and decreased in the IPF patient. The crackle rate was unchanged in the CHF patient. This crackle rate finding was typical of all the patients. 
A
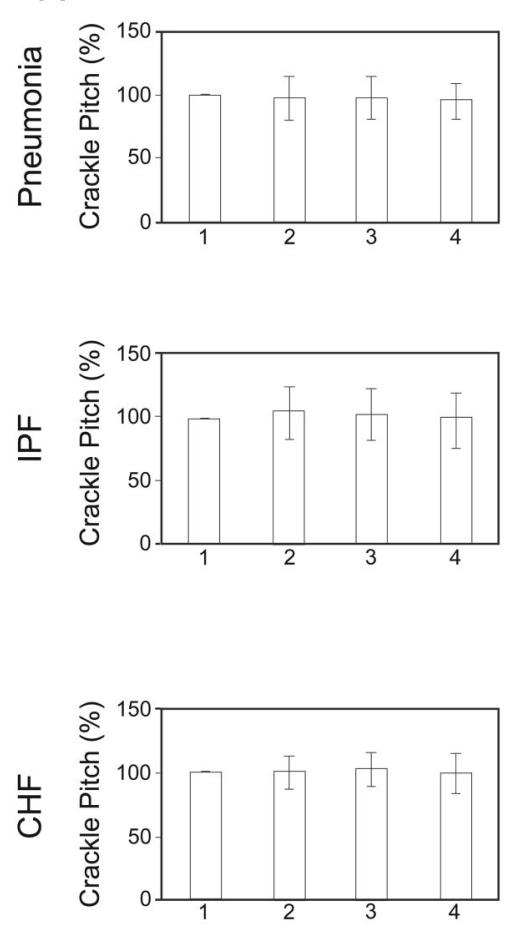

$\mathrm{B}$
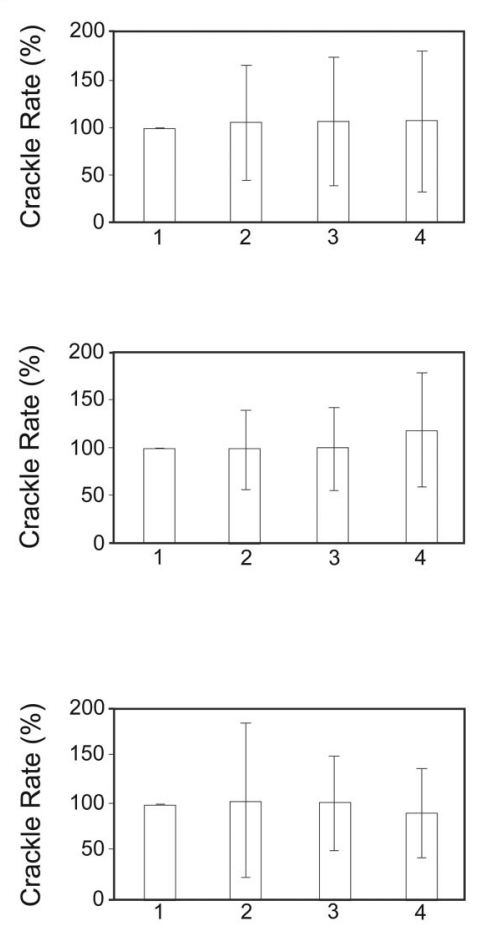

Fig. 2. Within-maneuver crackle variability in 3 groups of patients: pneumonia, interstitial pulmonary fibrosis (IPF), and congestive heart failure (CHF). A: Crackle pitch in 4 consecutive deeper-than-normal breaths. The crackle pitch in each breath is expressed as a percent of the crackle pitch in the first breath. B: Crackle rate in 4 consecutive deeper-than-normal breaths. The crackle rate in each breath is expressed as a percent of the crackle rate in the first breath.

Table 2. Within-Maneuver Crackle Pitch Variability*

\begin{tabular}{lcccc}
\hline \hline & $\begin{array}{c}\text { Normal } \\
\text { Breathing }\end{array}$ & $\begin{array}{c}\text { First Deeper } \\
\text { Than Normal }\end{array}$ & $\begin{array}{c}\text { Second Deeper } \\
\text { Than Normal }\end{array}$ & $\begin{array}{c}\text { Third Deeper } \\
\text { Than Normal }\end{array}$ \\
\hline Pneumonia & $12 \pm 8$ & $10 \pm 7$ & $11 \pm 6$ & $10 \pm 6$ \\
Congestive heart failure & $12 \pm 7$ & $9 \pm 8$ & $10 \pm 7$ & $12 \pm 8$ \\
Interstitial pulmonary fibrosis & $4 \pm 3$ & $8 \pm 5$ & $7 \pm 6$ & $8 \pm 8$
\end{tabular}

* Standard deviation in crackle pitch measured in all consecutive breaths in each patient is expressed as a percentage of the average crackle pitch during the entire 20-second recording, and then averaged between all patients (mean $\pm \mathrm{SD}$ ).

Table 3. Crackle Pitch During Entire 20-Second Recording*

\begin{tabular}{lcccc}
\hline \hline & $\begin{array}{c}\text { Normal } \\
\text { Breathing }\end{array}$ & $\begin{array}{c}\text { First Deeper } \\
\text { Than Normal }\end{array}$ & $\begin{array}{c}\text { Second Deeper } \\
\text { Than Normal }\end{array}$ & $\begin{array}{c}\text { Third Deeper } \\
\text { Than Normal }\end{array}$ \\
\hline Pneumonia & $267 \pm 55$ & $280 \pm 63$ & $283 \pm 60$ & $281 \pm 55$ \\
Congestive heart failure & $303 \pm 65$ & $293 \pm 60$ & $300 \pm 68$ & $298 \pm 60$ \\
Interstitial pulmonary fibrosis & $467 \pm 55$ & $452 \pm 58$ & $449 \pm 57$ & $467 \pm 51$
\end{tabular}

$\bar{*}$ Mean \pm SD Hz during entire 20-second recording, averaged among all patients.

In the pneumonia patients the only statistically significant change in crackle rate between breathing maneuvers was an increase in the crackle rate from normal breathing to the first deeper-than-normal breathing maneuver
$(P<.001)$ (Fig. 4). Crackle rate increased from the normal breathing to the first deeper-than-normal breathing maneuver in $39(80 \%)$ pneumonia patients. Crackle rate decreased in only 10 patients $(20 \%)$. 


\section{Crackle Pitch and Rate Do Not Vary Significantly During Automated-Auscultation}

Table 4. Within-Maneuver Crackle Rate Variability*

\begin{tabular}{lcccc}
\hline \hline & $\begin{array}{c}\text { Normal } \\
\text { Breathing }\end{array}$ & $\begin{array}{c}\text { First Deeper } \\
\text { Than Normal }\end{array}$ & $\begin{array}{c}\text { Second Deeper } \\
\text { Than Normal }\end{array}$ & $\begin{array}{c}\text { Third Deeper } \\
\text { Than Normal }\end{array}$ \\
\hline Pneumonia & $37 \pm 25$ & $31 \pm 24$ & $35 \pm 24$ & $31 \pm 25$ \\
Congestive heart failure & $34 \pm 34$ & $32 \pm 23$ & $34 \pm 27$ & $34 \pm 22$ \\
Interstitial pulmonary fibrosis & $22 \pm 14$ & $24 \pm 13$ & $36 \pm 20$ & $31 \pm 25$
\end{tabular}

* Standard deviation in crackle rate measured in all consecutive breaths in each patient is expressed as a percentage of the average crackle rate during entire 20 -second recording, and then averaged between all patients (mean $\pm \mathrm{SD}$ ).

Table 5. Average Crackle Rate* During Entire 20-Second Recording

\begin{tabular}{lcccc}
\hline \hline & $\begin{array}{c}\text { Normal } \\
\text { Breathing }\end{array}$ & $\begin{array}{c}\text { First Deeper } \\
\text { Than Normal }\end{array}$ & $\begin{array}{c}\text { Second Deeper } \\
\text { Than Normal }\end{array}$ & $\begin{array}{c}\text { Third Deeper } \\
\text { Than Normal }\end{array}$ \\
\hline Pneumonia & $8 \pm 7$ & $12 \pm 10$ & $10 \pm 6$ & $10 \pm 7$ \\
Congestive heart failure & $7 \pm 8$ & $7 \pm 6$ & $7 \pm 6$ & $6 \pm 5$ \\
Interstitial pulmonary fibrosis & $32 \pm 22$ & $27 \pm 19$ & $21 \pm 15$ & $24 \pm 17$
\end{tabular}

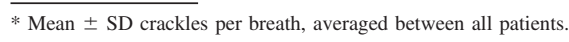

Table 6. Crackle Pitch in the 4 Breathing Maneuvers

\begin{tabular}{|c|c|c|c|c|c|}
\hline & $\begin{array}{l}\text { Normal } \\
\text { Breathing }\end{array}$ & $\begin{array}{l}\text { First Deeper } \\
\text { Than Normal* }\end{array}$ & $\begin{array}{c}\text { Second Deeper } \\
\text { Than Normal }\end{array}$ & $\begin{array}{l}\text { Third Deeper } \\
\text { Than Normal }\end{array}$ & $\begin{array}{l}\text { Absolute Pitch of } \\
\text { Crackles During First } \\
\text { Deeper Than Normal } \\
\text { (mean } \pm \text { SD Hz) }\end{array}$ \\
\hline Pneumonia & $97 \pm 15$ & 100 & $100 \pm 15$ & $100 \pm 18$ & $280 \pm 63$ \\
\hline Congestive heart failure & $100 \pm 23$ & 100 & $103 \pm 14$ & $92 \pm 33$ & $293 \pm 60$ \\
\hline Interstitial pulmonary fibrosis & $104 \pm 9$ & 100 & $100 \pm 6$ & $104 \pm 8$ & $452 \pm 58$ \\
\hline
\end{tabular}

The reverse was true in patients with IPF: the crackles significantly decreased during deep-breathing maneuvers, compared to normal breathing $(P=.022)$ (see Fig. 4B). Crackle rate decreased in the first deeper-thannormal maneuver, compared to normal breathing, in 12 IPF patients (67\%), and crackle rate increased in 6 patients $(33 \%)$.

In the CHF patients there were no consistent betweenmaneuver changes (see Fig. 4C). The average crackle rates were similar during normal and deep breathing. Crackle rate decreased from normal breathing to deep breathing in about as many patients as it increased.

To investigate whether the air-flow rate influenced crackle rate, we divided all the patients into 2 groups: one in which crackle rate increased from normal breathing to deeper-than-normal maneuver, and one in which crackle rate decreased. Then we calculated the average tracheal amplitude of each group (Table 7). The difference in amplitude change between those 2 groups was statistically significant in the pneumonia patients. This observation is consistent with the findings reported in Figure 4. In 39 patients, air flow during normal breathing was only $60 \%$ of that during deep breathing (see Table 7). In those patients crackle rate increased from normal breathing to deep breathing. In 10 patients, air flow during normal breathing was closer $(80 \%)$ to the air flow during deep breathing (see Table 7). In those patients crackle rate decreased from normal breathing to deep breathing. The difference in amplitude change between the 2 groups in the CHF and IPF patients was not statistically significant.

\section{Crackles Measured on Multiple Days}

Our crackle rate and pitch assessment with each patient were done at a single session. We do not know the variability from day to day in these patients. We know that crackle rate can vary, as seen in the 3 patients described in Figures 5, 6, and 7. Figure 5 shows the chest radiograph and crackle summary from a 42-yearold white male with left-lower-lobe pneumonia recorded 

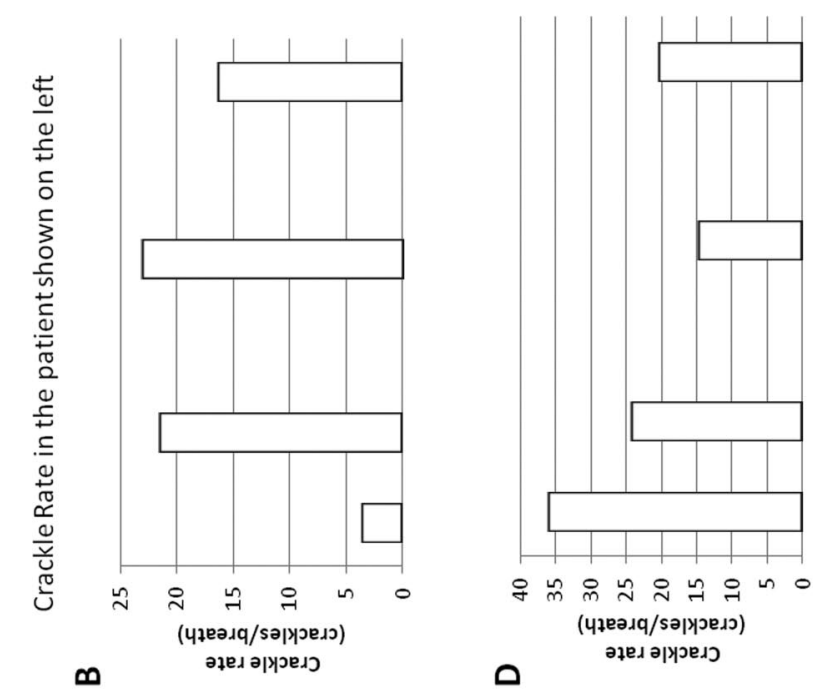

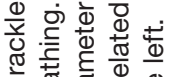

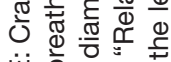
نं

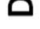
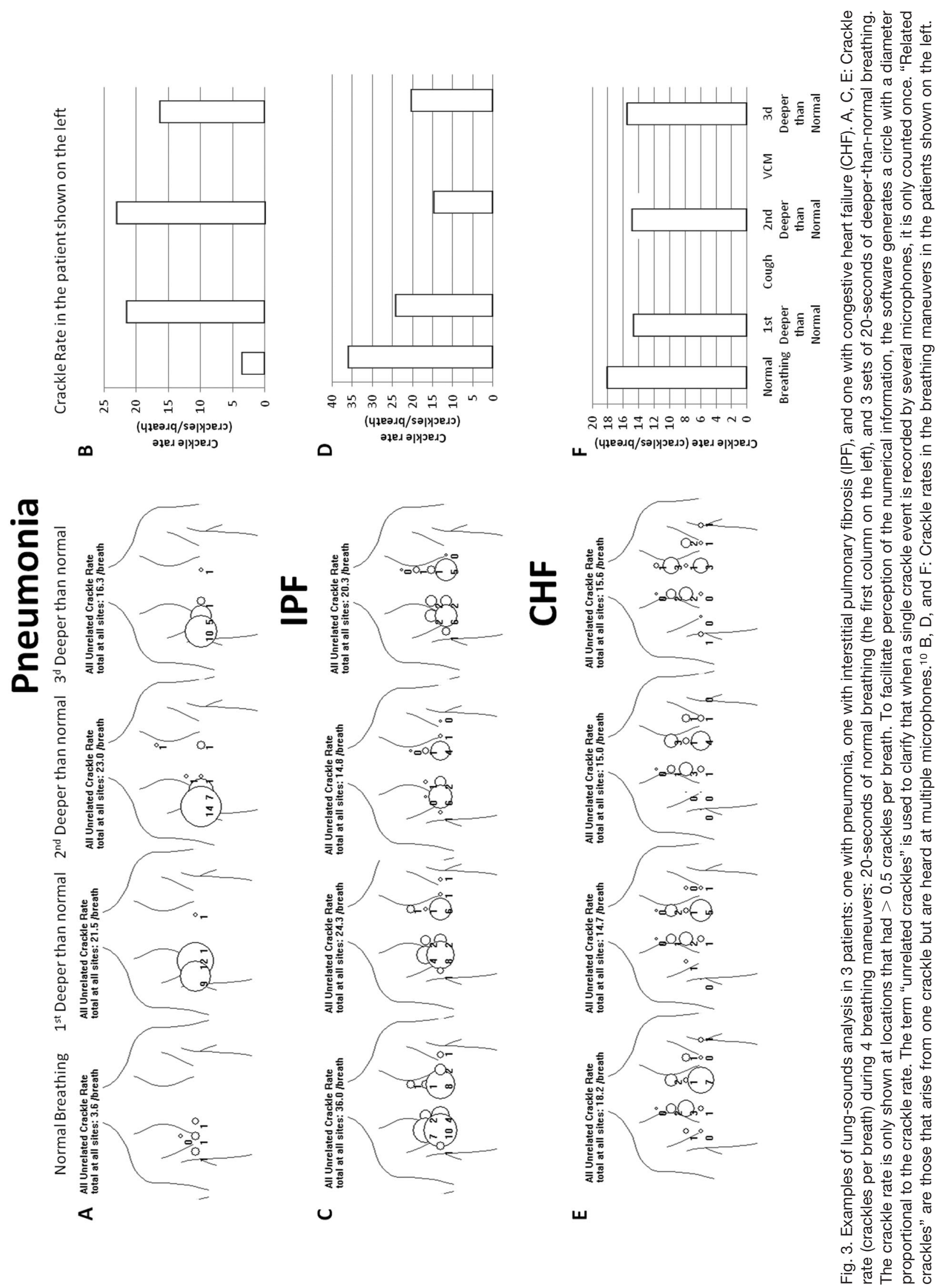

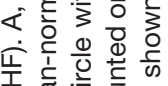

记

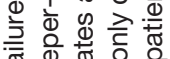

画 $\frac{0}{0} \frac{\pi}{0}$

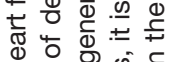

我

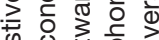

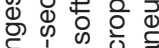

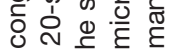

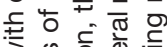

了.

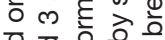

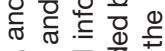

近需.

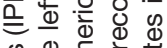

电吊

흥 व

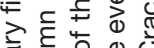

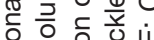

है

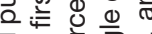

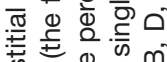

क人

. 

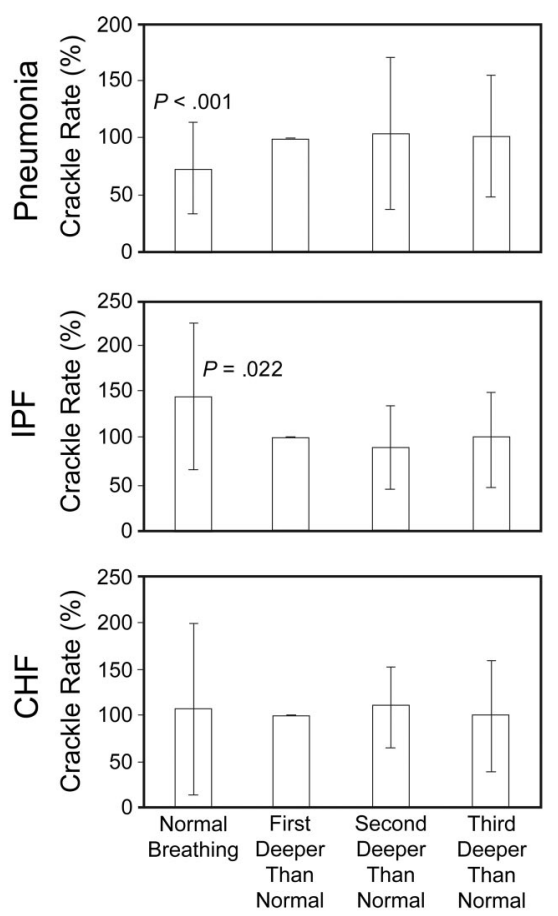

Fig. 4. Average crackle rates in patients with pneumonia, interstitial pulmonary fibrosis (IPF), and congestive heart failure (CHF). Each patient's crackle rate during normal breathing and during the second and third deeper-than-normal breathing maneuver is expressed as a percentage of his or her crackle rate during the first deeper-than-normal breathing maneuver.

over several weeks. His crackle rate decreased markedly as the disease resolved. Figure 6 shows the crackle summary of a 54-year-old female with CHF. She was treated with a diuretic, and the crackles decreased markedly after treatment. Figure 7 presents the findings from a 68-year-old Japanese male who presented with a slight cough in January 2010, and underwent spirometry and lung-sounds analysis. Crackles were heard at the right base, but few were heard on the left. In June he was reexamined and crackles were heard at both bases. His crackle count increased and his $\mathrm{FEV}_{1}$ and FVC decreased. A lung biopsy was subsequently done showing findings consistent with interstitial pulmonary fibrosis (see Fig. 7).

\section{Crackles in Atelectasis}

The observations presented above are only from patients with pneumonia, CHF, and IPF. The variability of crackles in other disease processes may be different, as seen in a patient with atelectasis. Figure 8 shows lungsounds analysis of a 69-year-old white male undergoing spinal anesthesia during surgery to remove a hydrocoele. Prior to the procedure no crackles were detected. Fourteen minutes into the operation, crackles were detected at most lung sites, with accentuation at the lung bases. After he took 3 deep breaths, the crackle rate returned to zero (see Fig. 8A). At 5-min intervals thereafter he was asked to breathe deeper than normal again. In every recording the crackle rate returned to zero after he took 3 deep breaths (Fig. 8B). We conclude that he developed crackles as a result of atelectasis. Unlike the stable crackles in our pneumonia, CHF, and IPF patients, atelectatic crackles disappeared after a few deep breaths.

\section{Discussion}

Crackles in all 3 conditions were surprisingly stable. Neither the average crackle rate, nor the average crackle pitch changed significantly from breath to breath or from one deeper-than-normal breathing maneuver to another, even when the maneuvers were separated by the cough or vital-capacity maneuver. This then provides evidence that crackle rate in a given examining session is a reproducible measurement, which implies that crackle rate can be serially measured to follow the course of an illness. There is a considerable body of clinical experience to support the observation that crackles in pneumonia and CHF decrease as the disease improves (see Figs. 5 and 6), and frequently increase if the disease worsens. Crackles are often absent if the patient has no other evidence of CHF. We did not do serial automated-auscultation sessions in the present study, but this is an appropriate goal of a future study.

We did, however, find significant changes in crackle rate from normal breathing to deeper-than-normal breathing in the pneumonia and IPF patients. During deeperthan-normal breathing the average crackle rate was greater

Table 7. Relationship of Tracheal Amplitude to Crackle Rate Change From Normal Breathing Maneuver to Deep Breathing Maneuver*

\begin{tabular}{lccr}
\hline \hline & $\begin{array}{c}\text { Normal Breathing } \\
\text { in the Group With } \\
\text { Increased Crackle Rate }\end{array}$ & $\begin{array}{c}\text { Normal Breathing } \\
\text { in the Group With } \\
\text { Decreased Crackle Rate }\end{array}$ & $\begin{array}{c}\text { First Deeper } \\
\text { Than Normal } \\
\text { in Both Groups* }\end{array}$ \\
\hline Pneumonia & $60 \pm 38(n=39)$ & $80 \pm 17(n=10)$ & 100 \\
Congestive heart failure & $63 \pm 40(n=24)$ & $54 \pm 34(n=21)$ & .02 \\
Interstitial pulmonary fibrosis & $41 \pm 27(n=6)$ & $57 \pm 35(n=12)$ & .15 \\
\end{tabular}

* As in Table 1, the first deeper-than-normal breathing maneuver is the reference level (100\%), and the tracheal amplitude during normal breathing is expressed as a percentage of that reference level (mean $\pm \mathrm{SD}$ ) 
A

Day 1

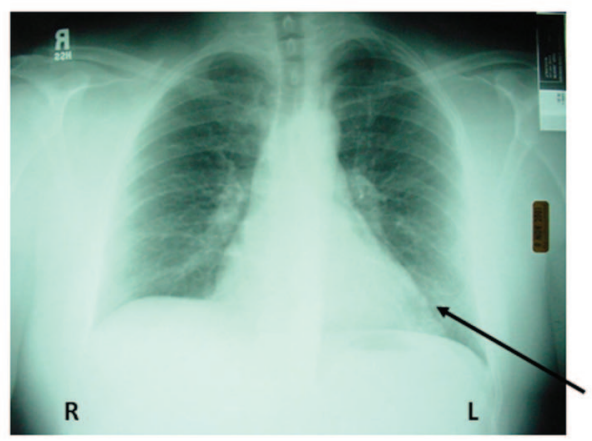

\section{Day 1}

B

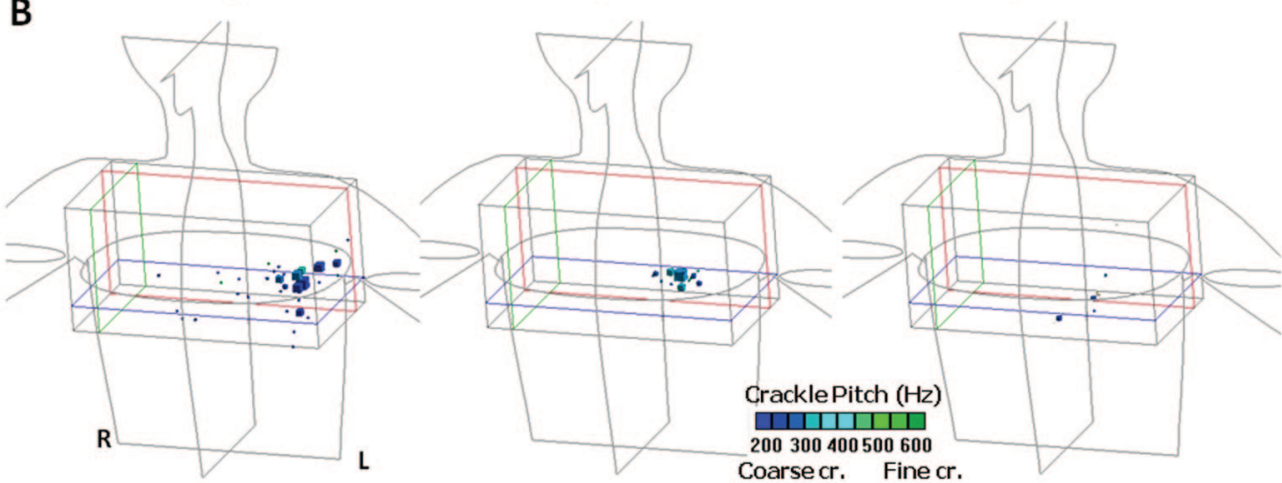

Day 11

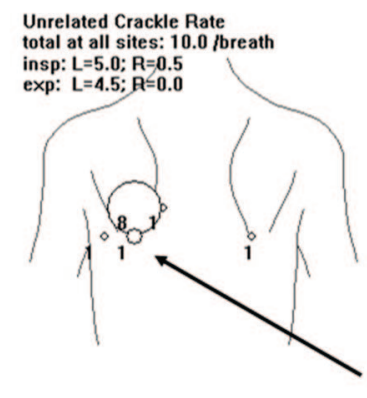

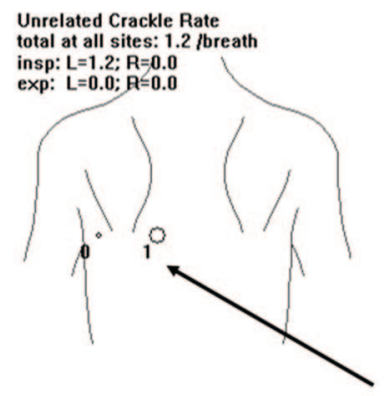

Unrelated Crackle Rate total at all sites: 1.2 /breat exp: $L=0.0 ; A=0.0$

D
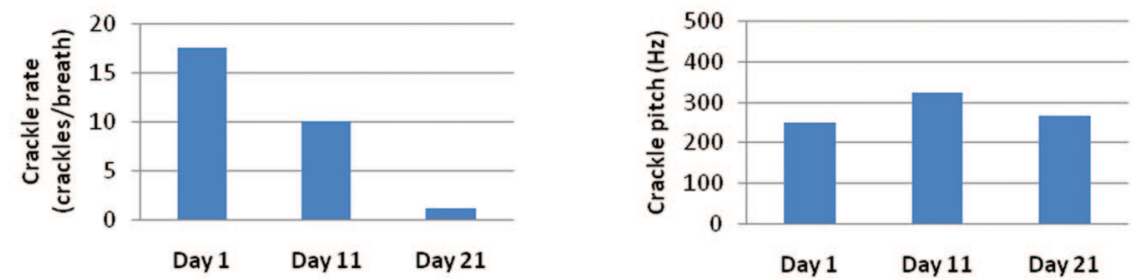

Fig. 5. Crackle summary and chest radiograph from a patient with left-lower-lobe pneumonia. A: Chest radiograph. Four of 6 board-certified observers (3 pulmonologists and 3 radiologists) agreed that the radiograph shows linear opacifications in the left lower lobe (arrow), consistent with pneumonia. B: Based on arrival-time differences at the microphones, the crackles were localized to the left lower lobe. In the 3-dimensional diagram the blue cubes are proportional to the crackle density. The crackle pitch is color-coded with a scale from blue (coarse crackle) to green (fine crackle). C: Crackle summary. The circle diameters are proportional to the crackle rate. Note the large number of crackles at the left base (arrows). These recordings were made during deeper-than-normal breathing maneuvers. D: Crackle rate and pitch during deeper-than-normal breathing. Crackles decreased markedly by day 21 , when the pneumonia cleared.

in the pneumonia patients and less in the IPF patients, compared to during normal breathing. We realize that this finding may have limited clinical value, but it may help clinicians considering the diagnosis of IPF in cases where they might otherwise not suspect it. We have found no literature documenting the misdiagnosis of IPF, but testi- 


\section{Before diuretic}

A

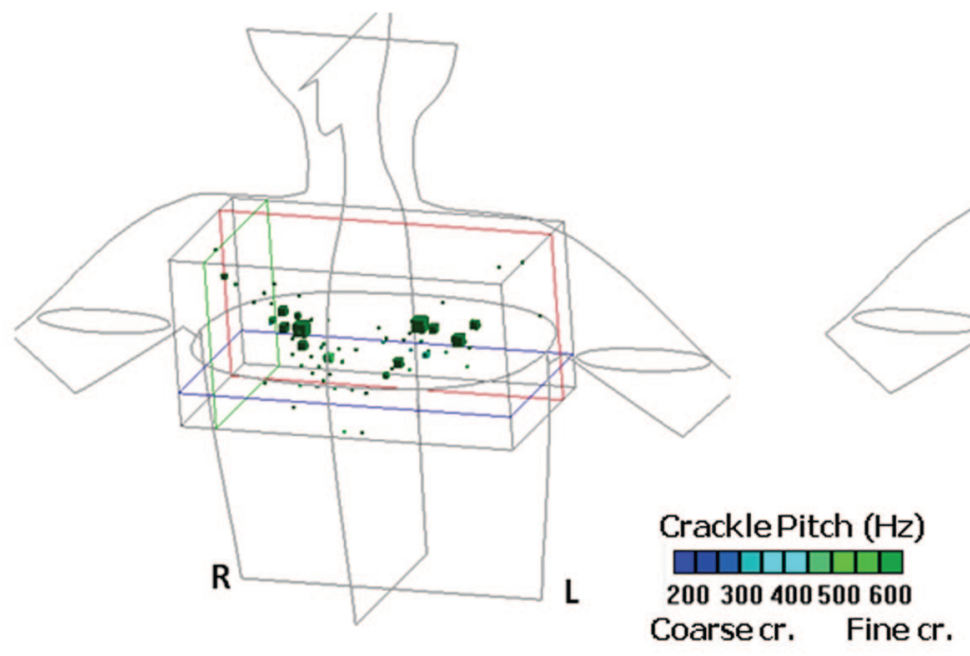

\section{After diuretic}

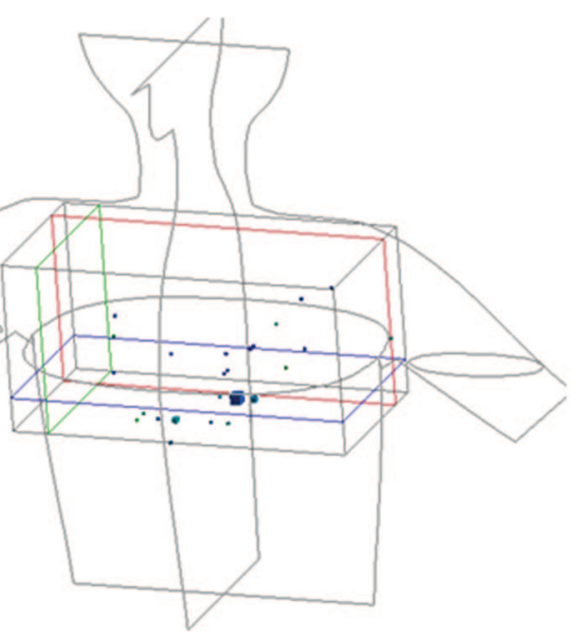

B

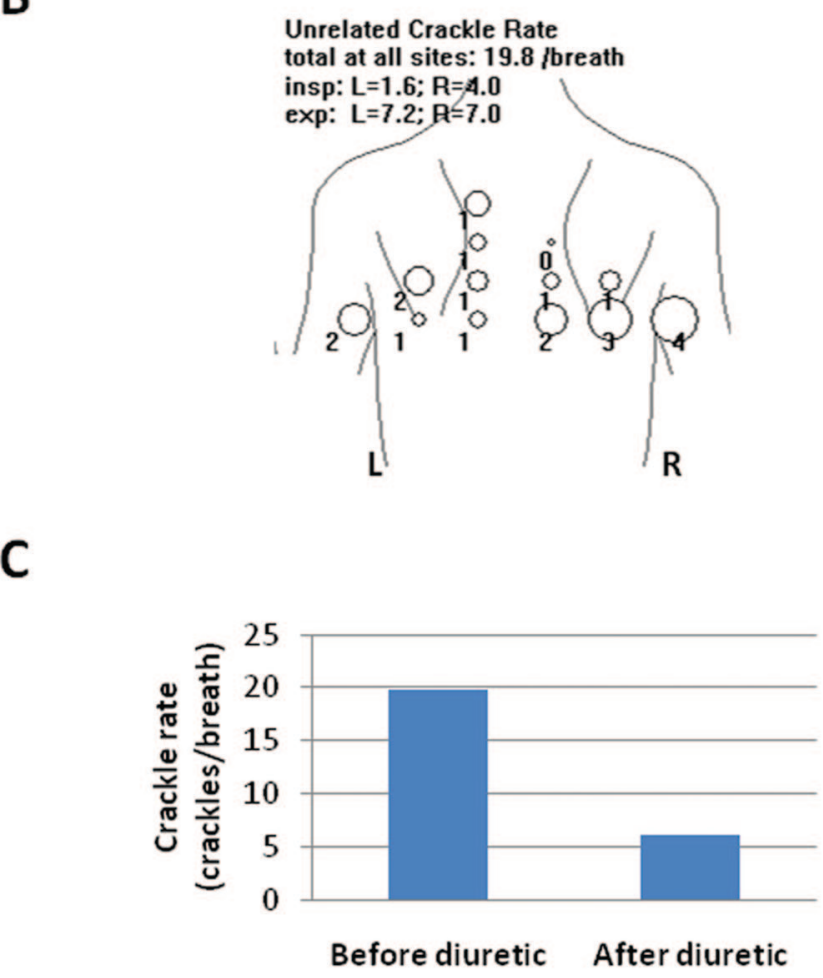

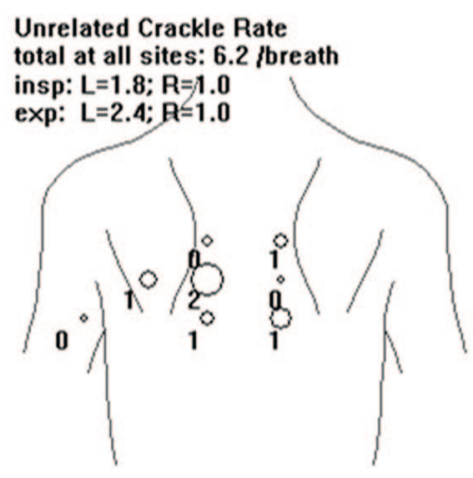

Fig. 6. Automated-auscultation findings (as in Fig. 5) from a 54-year-old female patient with congestive heart failure (CHF). A: The 3-dimensional diagram shows that the crackles were in the lung bases. B: Crackle summary. C: Crackle rate and pitch during deeperthan-normal breathing. The crackle rate decreased markedly after treatment with a diuretic.

monies of numerous clinicians with whom we have discussed this indicate that IPF is commonly misdiagnosed. Any clue that crackles are due to IPF rather than other conditions could be of some help. Unfortunately, decreased crackle rate on deep breathing also occurred in patients with CHF. As CHF is the most common erro- neous diagnosis in patients who have IPF, this makes this observation less useful when CHF is in the differential. The finding of the change in crackle rate on deep breathing provides some support for auscultation during both quiet and deep breathing, which could help in the diagnosis of pneumonia. 


\section{January, 2010}

A

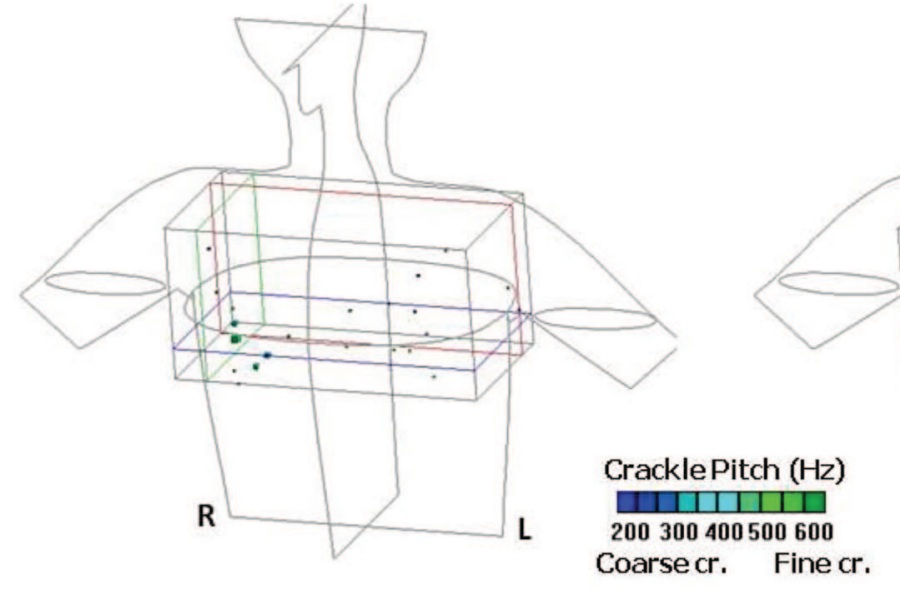

June, 2010

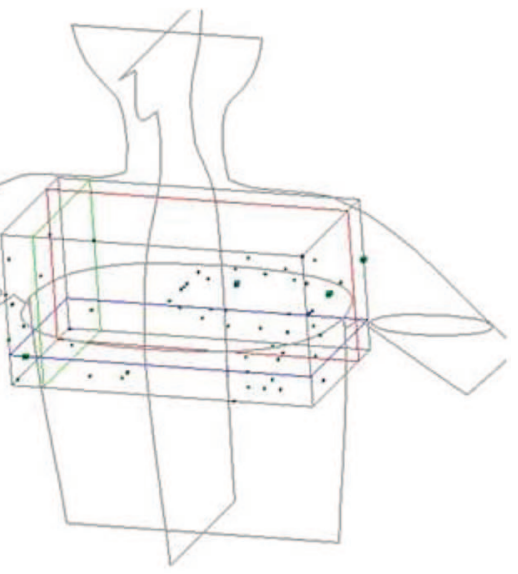

B
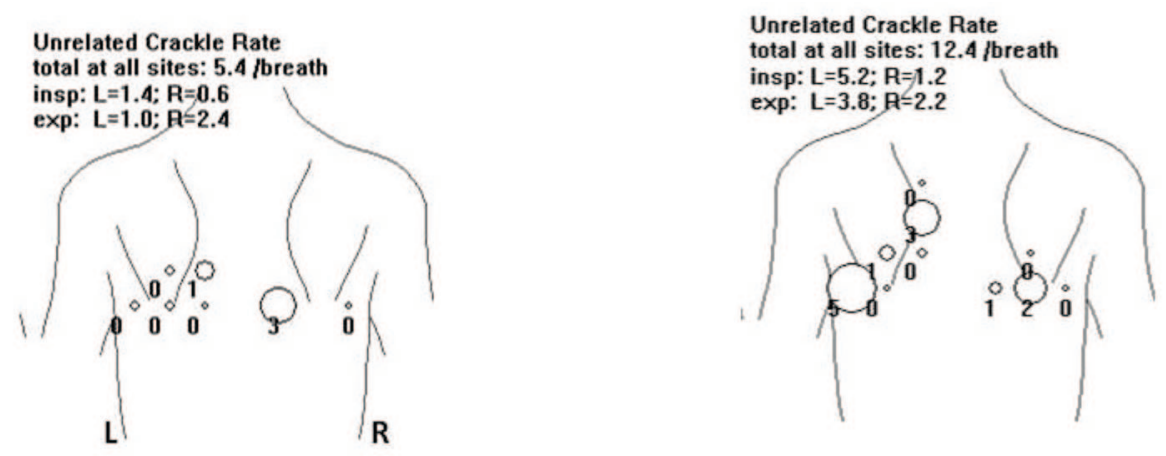

C
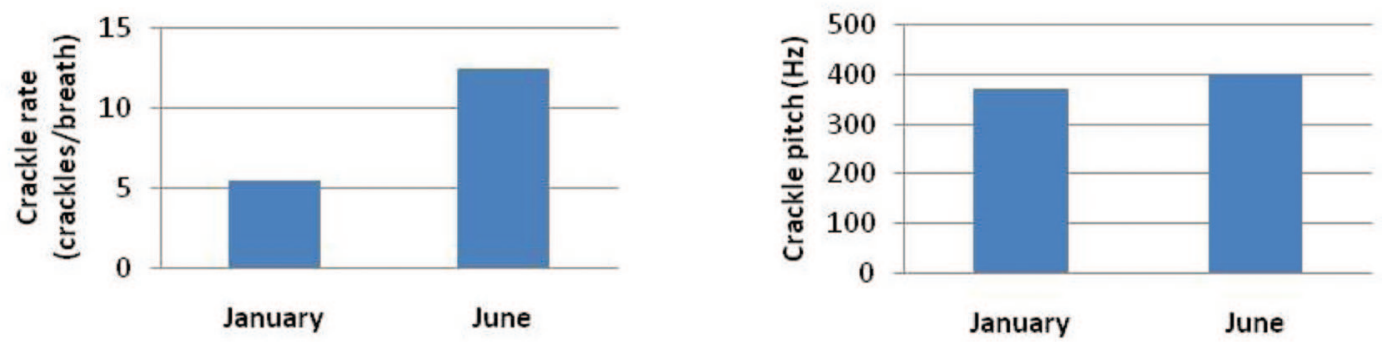

D

\begin{tabular}{|l|l|l|l|l|}
\hline & \multicolumn{1}{|c|}{ Peak Flow } & \multicolumn{1}{|c|}{ FEV $_{1}$} & \multicolumn{1}{c|}{ FVC } & \multicolumn{1}{c|}{ FEV $_{1} / \mathrm{FVC}$} \\
\hline January, 2010 & 500 & 2.56 & 3.04 & $84 \%$ \\
\hline June, 2010 & 500 & 2.15 & 2.84 & $76 \%$ \\
\hline
\end{tabular}

Fig. 7. Automated-auscultation findings (as in Fig. 5) from a 68-year-old Japanese male who presented with a slight cough in January 2010, and was reexamined in June 2010. A lung biopsy was subsequently done showing findings consistent with interstitial pulmonary fibrosis. A: The 3-dimensional crackle diagrams. B: Crackle summary. In January the crackles were mainly in the right base, whereas in June crackles were detected in both bases. C: Crackle rate and pitch during deeper-than-normal breathing. Crackles increased markedly in the 6 months between recordings. D: Spirometry found reduced $\mathrm{FEV}_{1}$ and forced vital capacity (FVC) in June.

That the crackle rate increased during deep breathing in most of the pneumonia patients and decreased in most of the IPF patients were unexpected findings. The explanation is unlikely to be due to the difference in air flow or 

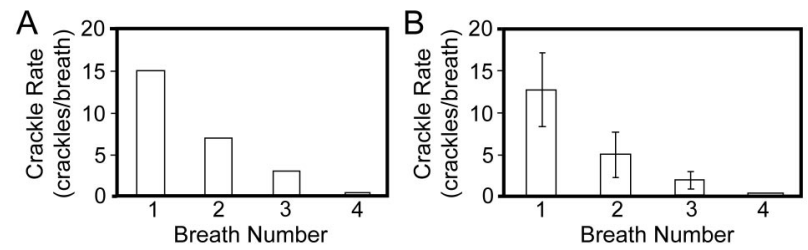

Fig. 8. Lung-sounds analysis of a 69-year-old white male undergoing spinal anesthesia during surgery to remove a hydrocoele. Every 5 minutes the patient was asked to take 4 deep breaths (numbered 1 through 4). A: Crackle rate during 4 consecutive deep breaths. B: Crackle rate averaged over 4 sets of 4 deep breaths, separated by approximately 5 minutes of quiet breathing. In every recording the crackle rate returned to zero after the deep breaths.

depth of respiration, since the tracheal amplitude was not significantly different between those with increased crackle rate and those with decreased crackle rate (see Table 7). A probable physiologic explanation for the deep-breathing crackles decrease in IPF is that crackles are less likely to occur in expanded lung. Some evidence to support the concept that crackles are more common in less expanded lungs comes from a study that found a gravitational dependence of crackles in patients with CHF. ${ }^{13}$ Crackles were more numerous in the left lung when the patient was in the left lateral decubitus position, and more numerous in the right lung in the right lateral decubitus position. Similarly, the crackles in IPF change with body position. Forgacs postulated that crackles were caused by the sudden equalization of gas pressure upstream and downstream from a closed airway. ${ }^{14} \mathrm{He}$ called attention to the observation that crackles in IPF are more numerous at the lung bases, and theorized that as the lung sits on its own weight, more airways tend to be closed in the dependent regions. The observation that the crackles in the patient with atelectasis presented in Figure 8 decreased with deep breathing is also consistent with crackles being more common in unexpanded lung regions. The explanation for more crackles in pneumonia is a bit more difficult, but perhaps it is due to greater airway recruitment during deeper-than-normal breathing. In any case, this was an unexpected finding and needs further study to assess its clinical value.

The crackle pitch in the patients with IPF was higher than in the patients with pneumonia or CHF (see Table 3). This difference in pitch has been previously reported. ${ }^{1}$ The common explanation is that crackles in IPF are probably produced in smaller airways than the crackles in pneumonia or CHF. In any case, this crackle pitch difference can be useful in distinguishing IPF from pneumonia or CHF. Another automated-auscultation variable, crackle transmission coefficient, can also help. Crackle transmission coefficient measures the degree of crackle sound transmission through the ipsilateral chest, as calculated from crackle family observation by multiple microphones. The crackle transmission coefficient is lower in IPF than in pneumonia or CHF, and the combination of crackle pitch and crackle transmission coefficient separates IPF from pneumonia and CHF more clearly than either measurement alone. ${ }^{10}$

We did not monitor air flow at the mouth. We chose to study the relationship of crackle characteristics to breathing maneuvers that can be performed at the bedside during routine physical examination. The patients in this study were instructed to breathe normally or more deeply by a technician who carefully observed their performance. This can be readily done in most patients. Measuring flow at the mouth would have been difficult in many of the patients we studied. The majority of the patients with CHF and pneumonia were too ill to have their flow measured at the mouth or to be sent to a laboratory for pulmonary function testing. In addition, devices that accurately measure flow at the mouth also alter the breathing pattern and minute ventilation. ${ }^{15-18}$ Instead we measured flow with a tracheal microphone, which is a reasonably accurate method. ${ }^{19-25}$ The tracheal sound amplitude during normal breathing was significantly lower than during deep breathing, which is objective evidence that the patients were taking deeper breaths.

Other unexpected observations have been made in lungsounds studies. To our surprise, we observed that about $15 \%$ of patients with pneumonia have squawks, ${ }^{26}$ which are short inspiratory squeaky sounds that have been described in diffuse IPF. ${ }^{27}$ Squawks in pneumonia were first described by Laënnec as "le crie d'un petit oiseau" (the cry of a small bird), almost 200 years ago, ${ }^{28}$ but were then forgotten by the medical community. Systematic studies of automated-auscultation recordings led to the rediscovery of the association of squawks with pneumonia. Such studies, which rapidly collect a large amount of objective acoustic information, offer the promise of uncovering other potentially useful associations of lung sounds with cardiopulmonary disorders.

\section{Conclusions}

The finding that crackle rate is reproducible in repeated measurements in a single automated-auscultation session shows that crackle rate can be used to follow the course of patients with CHF, pneumonia, and IPF. To further assess the clinical value of this observation, studies on whether individual practitioners using a stethoscope can be trained to reliably assess crackle rate and pitch should be done. We have evidence that lung-sounds assessment by highly qualified pulmonary specialists compares favorably to computerized assessment. A study to determine whether lesstrained clinicians can perform as well or be trained to do so is also indicated. 


\section{Crackle Pitch and Rate Do Not Vary Significantly During Automated-Auscultation}

\section{REFERENCES}

1. Murphy R. In defense of the stethoscope. Respir Care 2008;53(3): 355-369.

2. Bettencourt PE, Del Bono EA, Spiegelman D, Hertzmark E, Murphy RL Jr. Clinical utility of chest auscultation in common pulmonary disease. Am J Respir Crit Care Med 1994;150(5 Pt 1):1291-1297.

3. Pasterkamp H, Kraman S, Wodicka G. Respiratory sounds: advances beyond the stethoscope. Am J Respir Crit Care Med 1997;156(3 Pt 1):974-987.

4. Gavriely N. Breath sounds methodology. CRC Press; March 16, 1995.

5. Loudon R, Murphy RL Jr. State of the art: lung sounds. Am Rev Respir Dis 1984;130(4):663-673.

6. Murphy RL Jr, Del Bono E, Davidson F. Validation of an automatic crackle (rale) counter. Am Rev Respir Dis 1989;140(4):1017-1020.

7. Vyshedskiy A, Alhashem RM, Paciej R, Ebril M, Rudman I, Fredberg JJ, Murphy R. Mechanism of inspiratory and expiratory crackles. Chest 2009;135(1):156-164.

8. Bergstresser T, Ofengeim D, Vyshedskiy A, Shane J, Murphy R. Sound transmission in the lung as a function of lung volume. J Appl Physiology 2002;93(2):667-674.

9. Murphy RL, Vyshedskiy A, Power-Charnitsky VA, Bana DS, Marinelli PM, Wong-Tse A, Paciej R. Automated lung sound analysis in patients with pneumonia. Respir Care 2004;49(12):1490-1497.

10. Vyshedskiy A, Bezares F, Paciej R, Ebril M, Shane J, Murphy R. Transmission of crackles in patients with interstitial pulmonary fibrosis, congestive heart failure, and pneumonia. Chest 2005;128(3): 1468-1474.

11. Murphy RLH, Holford SK, Knowler WC. Visual lung sound characterization by time expanded wave-form analysis. N Engl J Med 1977;296(17):968-971.

12. Sovijarvi AH, Vanderschoot J, Earis JE. Computerized Respiratory Sound Analysis (CORSA) recommended standards for terms and techniques. Eur Respir Rev 2000;10:77;585-649.

13. Davidson FF, Murphy RL Jr. Gravity dependence of crackles: computers in critical care and pulmonary medicine. Plenum Publishing; 1983:279-285.
14. Forgacs P. The functional basis of pulmonary sounds. Chest 1978; 73(3):399-405

15. Ashkanazi J, Silverberg PA, Foster RJ, Hyman AI, Milic-Emili J, Kinney JM. Effects of respiratory apparatus on breathing pattern. J Appl Physiol 1980;48(4):577-580.

16. Gilbert R, Auchincloss JH Jr, Brodsky J, Boden W. Changes in tidal volume frequency and ventilation induced by their measurement. J Appl Physiol 1972;33(2):252-254.

17. Hirsch JA, and Bishop B. Human breathing patterns on mouthpiece or facemask during air, $\mathrm{CO}_{2}$, or low $\mathrm{O}_{2}$. J Appl Physiol 1982;53(5): 1281-1290.

18. Weissman C, Ashkanazi J, Milic-Emili J, Kinney JM. Effect of respiratory apparatus on respiration. J Appl Physiol 1984;57(2):475480.

19. Que CL, Kolmaga C, Durand LG, Kelly SM, Macklem PT. Phonospirometry for noninvasive measurement of ventilation: methodology and preliminary results. J Appl Physiol 2002;93(4):1515-1526.

20. Gavriely N, and Cugell DW. Airflow effects on amplitude and spectral content of normal breath sounds. J Appl Physiol 1996;80(1):5-13.

21. Kraman SS. The relationship between airflow and lung sound amplitude in normal subjects. Chest 1984;86(2):225-229.

22. Leblanc P, Macklem PT, Ross WR. Breath sounds and distribution of pulmonary ventilation. Am Rev Respir Dis 1970;102(1):10-16.

23. Shykoff BE, Ploysongsang Y, Chang HK. Airflow and normal lung sounds. Am Rev Respir Dis 1988;137(4):872-876.

24. Soufflet G, Charbonneau G, Polit M, Attal P, Denjean A, Escourrou $\mathrm{P}$, Gaultier C. Interaction between some tracheal sounds and flow rate: a comparison of some different evaluations from lung sounds. IEEE Trans Biomed Eng 1990;37(4):384-390.

25. Ploysongsang Y, Ilyer VK, Ramamoorthy PA. Characteristics of normal lung sounds after adaptive filtering. Am Rev Respir Dis 1989;139(4):951-956.

26. Paciej R, Vyshedskiy A, Bana D, Murphy R, Squawks in pneumonia, Thorax 2004;59(2):177-179.

27. Earis JE, Marsh K, Pearson, MG, Ogilvie CM, The inspiratory "squawk" in extrinsic allergic alveolitis and other pulmonary fibroses. Thorax 1982;37(12):923-926.

28. Laënnec RTH. A treatise on diseases of the chest. New York Academy of Medicine. New York: Hafner; 1962. 